\title{
The effects of restraint and restraint plus intermittent shock on ulcer formation in Brattleboro rats
}

\author{
CYRILLA H. WIDEMAN and HELEN M. MURPHY \\ John Carroll University, Cleveland, Ohio
}

\begin{abstract}
In order to examine the susceptibility of Brattleboro rats to stress as evidenced by ulcer formation, four conditions were studied: (1) unrestrained, nondeprived, (2) unrestrained, $29 \mathrm{~h}$ food deprived, (3) simple restraint, $29 \mathrm{~h}$ food deprived, and (4) restraint plus intermittent shock, $29 \mathrm{~h}$ food deprived. In the unrestrained and unrestrained-plus-29-h-food-deprived conditions, neither Brattleboro rats nor control (Long-Evans) animals developed ulcers. Differences appeared in the simple restraint and restraint plus intermittent shock conditions. In both of these conditions, Brattleboro rats developed more ulcers in the glandular portion of the stomach. It is concluded that Brattleboro rats show an enhanced reaction to stress as evidenced by ulcer formation.
\end{abstract}

It has been over two decades since the Brattleboro rat (DI) was discovered. These animals lack the hormone vasopressin and thus have the pathological disorder known as diabetes insipidus (Valtin \& Schroeder, 1964). Sokol and Zimmerman (1982) have reported alterations of other hormones in the plasma of these rats. For example, levels of oxytocin, follicle stimulating hormone, renin, and angiotensin II are increased in DI rats and levels of adrenocorticotropic hormone and aldosterone are decreased in such animals. There is conflicting evidence concerning variations in the level of plasma corticosterone. In addition to hormonal imbalances, DI rats show dramatic alterations in several plasma constituents when compared with Long-Evans (LE) control animals (Murphy \& Wideman, 1982).

Studies have indicated that because of hormonal alterations in DI rats, they may be more susceptible to stress than normal animals (Arimura, Saito, Bowers, \& Schally, 1967; Gash, Warren, Dick, Sladek, \& Ison, 1982; Lutz-Bucher \& Koch, 1982; McCann, Antunes-Rodrigues, Naller, \& Valtin, 1966; Wiley, Pearlmutter, \& Miller, 1974; Yates, Russel, Dallman, Hedges, McCann, \& Dhariwal, 1971). Ulcer development is one index of responsiveness to stress, as evidenced by the name "stress ulcer" proposed by Brodie (1971). The purpose of the present study was to determine the susceptibility of DI rats to stress utilizing the criterion of ulcer induction.

\section{METHOD}

Subjects

The subjects used were 40 male DI and 40 male LE control

The authors mailing address is: Department of Biology, John Carroll University, Cleveland, Ohio 44118. rats. Valtin (1982) suggests that the best control for a homozygous DI rat is a LE rat from the same colony that is used periodically for outbreeding and the production of "new" heterozygotes. This practice not only avoids excessive inbreeding but also provides controls that are genetically similar to the rats that carry the Brattleboro gene. Murphy and Wideman (1982), too, suggest that in experiments utilizing Brattleboro rats a control group of LE rats be employed. In the present study, the rats were 5 weeks old when purchased from Blue Spruce Farms, Inc. Prior to testing, the animals were kept in individual home cages for 2 weeks, with ad-lib access to food and water, and were placed in alternating periods of light and darkness each day. The lights went on at 8:00 a.m. and off at 8:00 p.m. Room temperature was maintained at $72^{\circ}-74^{\circ} \mathrm{F}$. The DI and LE rats were subdivided into four groups of 10 animals each in order to examine four different conditions: (1) unrestrained, nondeprived (2) unrestrained, $29 \mathrm{~h}$ food deprived (3) simple restraint, $29 \mathrm{~h}$ food deprived, and (4) restraint plus intermittent shock, $29 \mathrm{~h}$ food deprived.

\section{Procedure}

A matched pair of rats (one DI and one LE) was utilized in all testing sessions. In the unrestrained, nondeprived condition, the animals were sacrificed between 3:00 and 3:15 p.m. In the unrestrained, 29-h-food-deprived state, the animals were sacrificed at the same time after having been appropriately food deprived. In the condition of simple restraint and restraint plus intermittent shock, all animals were food deprived for $24 \mathrm{~h}$ prior to testing.

The basic equipment employed for the third and fourth conditions was similar to that of Weiss (1970) as modified by Murphy, Wideman, and Brown (1979). In the condition of simple restraint, the rats were placed in adjacent boxes, each containing a hardware-cloth tube that was used to restrain the rats. As in Weiss's apparatus, forward and backward movement was allowed in each tube, but the animals were unable to turn around. Constant access to water was supplied. Through a movable plastic back wall in each cage, adjustments could be made for size and weight variations. Electrodes were attached to the tail of each animal and held in place with tape on a protrusion in the back wall. Although the electrodes were attached in the simple restraint condition, the animals never received any shock. The animals were placed in the test cages for $5 \mathrm{~h}$. The sessions began between 10:00 and 10:15 a.m. and terminated between 3:00 and 3:15 p.m. 
In the condition of restraint plus intermittent shock, the same procedure as for simple restraint was followed, except that in the test cage the animals received a shock of $3.5 \mathrm{~mA}$ of $2 \mathrm{sec}$ duration through tail electrodes every $50 \mathrm{sec}$. Because the matched pairs were wired in series, the shocks received were equal in duration and had a similar current intensity. The stress sessions lasted $5 \mathrm{~h}$. In all four conditions, the animals were sacrificed by decapitation and the stomachs were removed immediately and examined for ulcers. Ulcers were defined as acute gastric lesions that were reddish brown in color. Some lesions were focal and circumscribed, whereas other lesions were irregular and linear, and tended to parallel folds of the glandular mucosa.

\section{RESULTS}

In the unrestrained, nondeprived and the unrestrained, 29-h-food-deprived conditions, no animals developed ulcers in either the rumenal or glandular portion of the stomach. In the condition of simple restraint, all DI and 4 of 10 LE animals developed ulcers in the glandular portion of the stomach. Figure 1 summarizes the results of this condition. The mean total length of ulcers for the DI group was $19.5 \mathrm{~mm}$, and the mean total length for the LE group was $2.7 \mathrm{~mm}$. A t test indicated that there was a significant difference at the .03 level. All ulcers found in a given animal were measured, and total measures were then added and a group mean was calculated over this cumulative score derived from each animal. Animals that had no ulcers were included in the mean.

In the condition of restraint plus intermittent shock, all DI and LE animals developed ulcers in the glandular portion of the stomach. Figure 2 summarizes the results of this condition. The mean

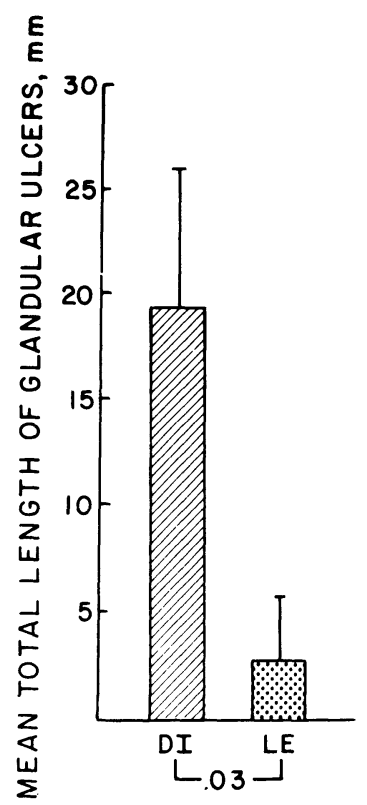

Figure 1. Mean total length of glandular stomach ulcers in DI and LE animals in the condition of simple restraint.

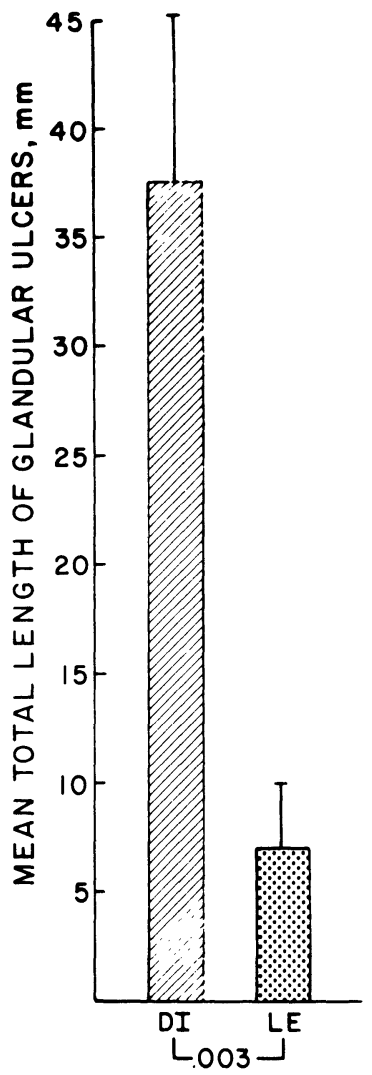

Figure 2. Mean total length of glandular stomach ulcers in DI and LE animals in the condition of restraint plus intermittent shock.

total length of ulcers for the DI group was $37.7 \mathrm{~mm}$ and the mean total length of ulcers for the LE group was $7.4 \mathrm{~mm}$. There was a significant difference at the .003 level.

Comparing variations within each group, the condition of restraint plus intermittent shock produced significantly more ulceration in both DI and LE animals than did the condition of simple restraint. Differences were at the .05 level in both instances. No rumenal ulcers were noted in DI or LE animals in the conditions of simple restraint and restraint plus intermittent shock.

\section{DISCUSSION}

The results of this experiment show that the conditions of restraint and restraint plus intermittent shock result in "stress ulcers" in both DI and LE animals. Conditions 1 and 2 (unrestrained, nondeprived and unrestrained, $29 \mathrm{~h}$ food deprived) produced no glandular ulcers. It is interesting to note that, although the animals were food deprived for $29 \mathrm{~h}$, the second, third, and fourth conditions did not yield rumenal ulcers that are characteristic of the "starvation ulcer" syndrome (Pare \& Temple, 1973). Restraint plus intermittent shock produced 
significantly more ulcers than did simple restraint in both experimental and control animals. Thus, the severity of stress may be correlated with the amount of glandular ulcer development. Under both conditions (restraint and restraint with intermittent shock), DI animals showed an exaggerated response to the stressor as compared with the controls. Consequently, it would appear that the lack of vasopressin or physiological results of this deficit render DI animals more sensitive to stress than control animals.

\section{REFERENCES}

Arimura, A., Saito, T., Bowers, C. Y., \& Schally, A. V. Pituitary-adrenal activation in rats with hereditary hypothalamic diabetes insipidus. Acta Endocrinologica, 1967, 54, 155-165.

Brodie, D. A. Stress ulcer as an experimental model of peptic ulcer disease. In C. J. Pfeiffer (Ed.), Peptic ulcer. Philadelphia: Lippincott, 1971.

Gash, D. M., Warken, P. H., Dick, L. B., Sladek, J. R., \& Ison, J. R. Behavioral modification in Brattleboro rats due to vasopressin administration and neural transplantation. Annals of the New York Academy of Sciences, 1982, 394, 672-688.

LUTZ-Bucher, B., \& Косн, B. Influence of posterior pituitary hormones on the pituitary-adrenocortical response to neurogenic stress in the Brattleboro rat. Annals of the New York Academy of Sciences, 1982, 394, 634-638.
McCann, S. M., Antunes-Rodrigues, J., Naller, R., \& Valtin, H. Pituitary-adrenal function in the absence of vasopressin. Endocrinology, 1966, 79, 1058-1064.

Murphy, H. M., \& Wideman, C. H. Basic alterations in serum levels of several chemical substances in Brattleboro rats. Annals of the New York Academy of Sciences, 1982, 394, 270-274.

Murphy, H. M., Wideman, C. H., \& Brown, T. S. Plasma corticosterone levels and ulcer formation in rats with hippocampal lesions. Neuroendocrinology, 1979, 28, 123-130.

Pare, W. P., \& Temple, L. J. Food deprivation, shock stress and stomach lesions in the rat. Physiology \& Behavior, 1973, 11, 371-375.

Sokol, H. W., \& Zimmerman, E. A. The hormonal status of the Brattleboro rat. Annals of the New York Academy of Sciences, 1982, 394, 535-548.

VAlTIN, H. The discovery of the Brattleboro rat, recommended nomenclature, and the question of proper controls. Annals of the New York Academy of Sciences, 1982, 394, 1-9.

Valtin, H., \& Schroeder, H. A. Familial hypothalamic diabetes insipidus in rats (Brattleboro strain). American Journal of Physiology, 1964, 206, 425-430.

WEISS, J. M. Somatic effects of predictable and unpredictable shock. Psychosomatic Medicine, 1970, 32, 397-408.

Wiley, M. K., Pearlmutter, A. F., \& Miller, R. E. Decreased adrenal sensitivity to ACTH in the vasopressin-deficient rat. Neuroendocrinology, 1974, 14, 257-270.

Yates, F. E., Russel, S. M., Dallman, M. F., Hedges, G. A., McCann, S. M., \& Dhariwal, A. P. S. Potentiation by vasopressin of corticotropin releasing factor. Endocrinology, 1971, 88, 3-15.

(Manuscript received December 3, 1982; revision accepted for publication February 14, 1983.) 